\title{
Learning materials: their use and evaluation
}

\author{
JUNE NASH \\ clo The Leprosy Mission International, 80 Windmill Road, Brentford, \\ Middlesex TW8 OQH, UK (Tel. +44-181-569-7292)
}

Accepted for publication 16 July 1999

\section{Introduction}

The training role within leprosy programmes is becoming increasingly important as integration takes place. Over the years, countries and individuals have developed their own materials, so that there is a plethora of material available. TALMilep and INFOLEP, joint projects of the International Federation of Anti-leprosy Associations (ILEP) try to keep field workers up to date with what is available and maintain some quality control. ${ }^{1}$ For many end users of the materials the questions of selection, quality and appropriateness still remain. Many health workers are just grateful to have any learning material at all, so clinics may be festooned with attractive but unintelligible glossy posters and bookshelves filled with unopened high-powered technical tomes. The indiscriminate use of learning materials also means that students with glazed eyes sit through videos that are difficult to translate into their work situations, and patients with numbed minds endure slide shows and illustrated lectures on the nature of leprosy that do not answer their questions. We need to be as discerning and selective in our use of learning materials as we are in our use of drugs to avoid learning-resistance and allergy.

\section{Why use learning materials?}

Learning materials are an aid to the learning process. They should not be for the benefit of the instructor or something that must be used all the time. They must facilitate the students' learning. They should:

- Arouse and maintain interest.

- Simplify instruction.

- Aid retention.

- Stimulate active thinking.

- Accelerate learning as more senses are involved. ${ }^{2}$ 


\section{Learning materials and adult learning}

Adult learning is different from that of children. In order to evaluate and use learning materials properly, we need to understand a little about the theory of learning. Education and learning are different, education emphasizes the educator, whilst learning emphasizes the person in whom the change is expected to occur. Learning can be defined as the process of gaining knowledge and/or expertise. It is this change of behaviour and gaining of skills and knowledge that we particularly need to achieve in leprosy training and health education. Six core principles have been identified in the practice of adult learning; ${ }^{3}$ these are:

- Learner's need to know.

- Self concept of the learner.

- Prior experience of the learner.

- Readiness to learn.

- Orientation to learning.

- Motivation to learn.

These are perspectives that come directly from the learner, and we need to take them into consideration in our teaching and use of learning materials if we want to have effective adult learning.

Health workers, particularly general health workers, do not need to know everything about leprosy, they are too busy to be interested in theory for theory's sake but they generally learn better if they are taught the why, what and how. You need to consider whom the person is that you are teaching; this is particularly true for health promotion. Ask these questions: How will they best learn? Do they like to find out for themselves? Will they learn better as partners in the process? Adults are not blank sheets. They have resources of experience and come complete with mental models and belief systems that need to be taken into account and built upon. They are ready to learn when the learning is life related, or helps them to develop new skills. They like to learn in context and in a problem centred way rather than with just theory. Their motivation for learning may be based on the intrinsic value of the learning but they will also want to consider the personal payoff for the learning.

This means that learning materials must have the following characteristics; they must be:

- Practical.

- Relevant to the learner's situation.

- Building upon existing knowledge.

- Problem centred.

- Logical.

- Clear.

- Rewarding.

They should be interactive and participatory, so that learners can easily apply the learning to their context and situations. This is particularly true for PHC workers in developing countries. In my experience of asking learners around the world how they learn, passive methods such as reading rate very low for most PHC workers. They learn much more by trying and doing. This means that the clarity and logical plan of written 
materials becomes much more important. Study guides and exercises should also be used with text books and manuals. ${ }^{4}$ Research has also shown that the age of the learner may influence learning preferences. ${ }^{5}$ One of the possibilities that we should also not overlook is to include participant involvement in the development of learning materials. This can be particularly empowering in health education. The materials produced are reflective of the people, locale and the language and therefore are powerful models that people can identify with. ${ }^{6}$

\section{Learning and memory}

Three kinds of memory have been identified, ${ }^{7}$ visual, auditory and kinaesthetic. Visual learners find it easy to take in information through visual media, charts and diagrams. Auditory learners take in their information through the spoken word, and kinaesthetic learners need to get physically involved; they enjoy trying things out and experimenting. In practice, most people use a combination of all three types of memory, but they generally dominate in one style and express a preference for one other. It is also helpful to look at the traditional learning methods used to see the cultural preferences for learning. Learning materials can be used interactively to develop the three kinds of memory strengths. This means making sure that there are good visuals in the material or asking the learners to make diagrams of the information, encourage the learners to read the words out, discuss the materials and summarize information. Physical involvement can include underlining, filling in sections of the material and practical assignments. Much has been written about the percent retention versus method of input, the accepted statistics are found in Figure 1. This again points to the need to be interactive in our use of learning materials. The 'banking' method of education, where students passively receive the teacher's wealth, has been criticized by Freire. ${ }^{8}$ Participatory and interactive use of learning materials are keys to the educational process, particularly in health education where learning cannot be separated from action.

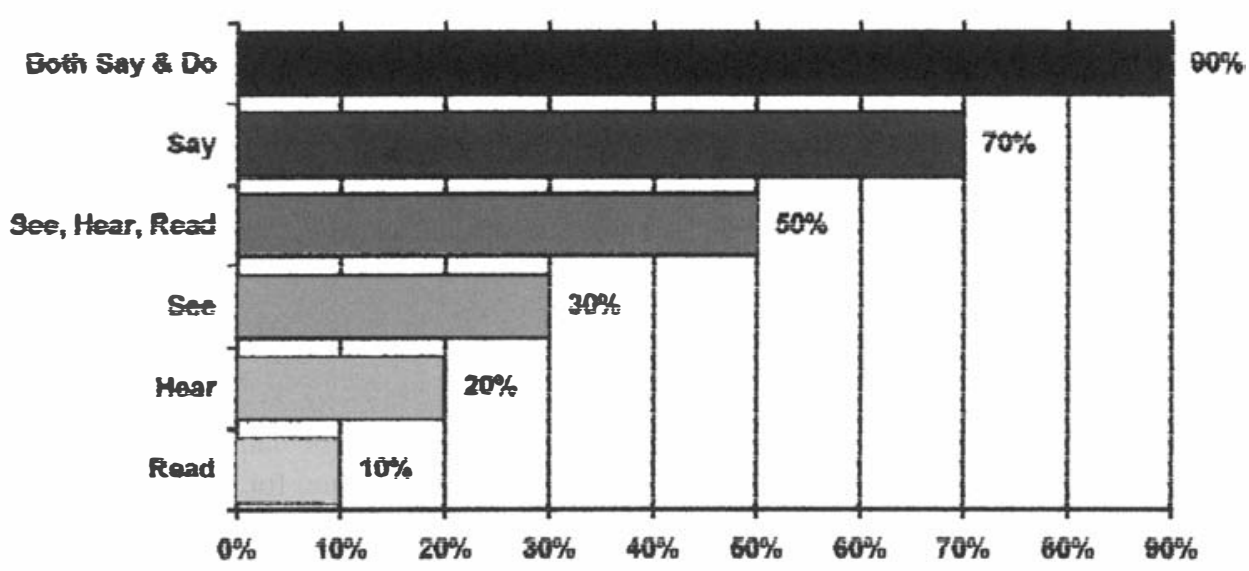

Figure 1. Percent retention versus method of input. 


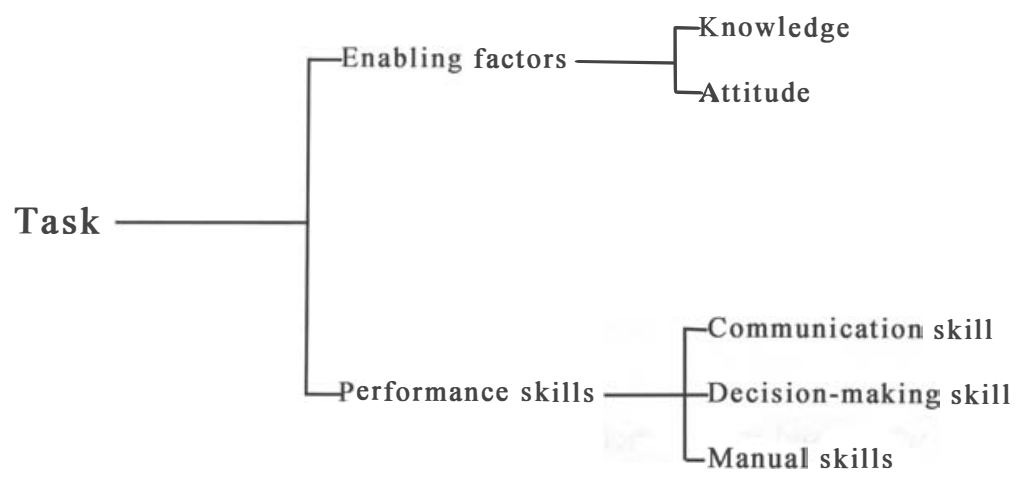

Figure 2. Task analysis model (Abbatt and McMahon).

\section{Types of learning}

Three distinct types of learning need to be considered when teaching and using learning materials. These are skills, attitude and knowledge. Although these are interlinked, learning materials often concentrate on providing knowledge learning and neglect the attitude and skills learning. It is quite helpful to break down health tasks into knowledge, attitude and skills. Abbatt ${ }^{9}$ breaks this down further into knowledge, attitude and performance skills. This model is helpful for teaching health workers, since it helps the teacher to include all the learning necessary for performance and competency in each of the tasks. It is also helpful to consider learning materials under the same headings, so that we do not overload health workers with knowledge based materials but also use materials to help the learner consider his attitudes and learn performance skills (Figure 2).

Table 1 gives some idea of learning materials and their use in the different types of learning. Written materials are primarily knowledge based, they can address some attitude issues but their success in this may relate to the culture of the people who read them. People who are influenced by the power of the written word will be more likely to

Table 1. Learning materials and Abbatt's learning model (J. Nash, 1999)

\begin{tabular}{lllllc}
\hline Learning material & Knowledge & Attitude & $\begin{array}{c}\text { Communication } \\
\text { skills }\end{array}$ & $\begin{array}{c}\text { Decision } \\
\text { making skills }\end{array}$ & $\begin{array}{c}\text { Manual } \\
\text { skills }\end{array}$ \\
\hline Video & Fair & Good & Good & Excellent & Fair \\
Leaflets & Excellent & Fair & Poor & Poor & Poor \\
Self learning books & Excellent & Fair & Poor & Poor & Poor \\
Books & Excellent & Fair & Poor & Poor & Poor \\
Posters & Excellent & Good & Poor & Fair & Poor \\
Teaching charts & Excellent & Good & Poor & Good & Poor \\
Check lists & Fair & Poor & Good & Poor & Good \\
Slides & Excellent & Poor & Poor & Excellent & Fair \\
CD ROMS & Good & Fair & Poor & Excellent & Fair \\
Simulation games & Fair & Excellent & Excellent & Excellent & Fair \\
PBL packages & Good & Fair & Good & Pxcellent & Poor \\
Video camera & Poor & Good & Excellent & Fair \\
\hline
\end{tabular}


change their attitudes than those who do not value the written word as much as seeing and doing.

Static visual materials (slides, posters, teaching charts) are also good for imparting knowledge, but may be used interactively to promote decision making skills by showing them and then asking questions to the learners or using them as illustrations in a problem centred approach. They may also help to influence attitudes, but we need to be aware that attitudes can be influenced for both good and ill when using visuals. Slides of badly disfigured patients or negative images can increase stigma even although they may be medically 'interesting'.

Animated visual material such as videos and films should not be used primarily for knowledge, but when used in conjunction with discussions in an interactive way can help change attitudes and promote decision making.

Interactive materials such as using video cameras, CD ROMs and problem based materials are more likely to help learners to gain skills, particularly in the area of decision making. This is one of the strengths of problem-centred learning programmes in which the learning is interactive and solving the problem is the focus of the learning process. ${ }^{10}$

Manual skills are particularly difficult to teach with learning materials and whilst animated visuals may help, there is no substitute for demonstration and practice.

It will be obvious from the above that the quality of materials is important if they are to achieve any of the learning objectives. Poor materials may not even be able to help the learner gain knowledge, let alone the more difficult learning attributes of skills and attitudes.

As well as using materials properly, it is important to evaluate them for quality and effectiveness. This is particularly true when developing materials.

\section{What makes good learning material?}

User-friendly written learning materials need to contain the right material in a logical and well presented form. They should be at the level of the learners and clear in their language and style. Several criteria have been developed to measure user friendliness. They look at simplicity of language, clarity of expression, logical sequence, page layout, pictures, style of writing and availability. ${ }^{11,12}$ Clarity of language is important, particularly where materials are developed for use in a second language. Clarity is generally measured by looking at sentence length, use of active verbs, abstract ideas, and technical jargon. Many modern word processors do this automatically. The Cloze test is specific for assessing if the language is understandable to the target group. A test group is given a sample of the material with every 'nth' word or randomly selected words deleted from the text. The group is then asked to supply the missing words. This test has been used in several Asian and African languages, as well as English.

Visual materials also need testing. Sociological and educational differences have a large effect on picture understanding, ${ }^{13}$ and since materials are often developed by the urban educated elite for the rural illiterate poor, there can be serious communication gaps. Pictures should be shown to the target audience and a series of simple questions asked such as: What is happening in this picture? What is this? Can you tell me what this diagram is saying? The same evaluation can be applied to animated visual materials such as videos. Viewers should be asked to summarize the message; to say which sections they like the best and why; and 
which sections they found confusing. Again the test viewers should be drawn from the proposed target audience rather than a group of trainers or 'experts'.

The pre-testing of materials is very important not only to avert expensive disasters, but also to make sure that the goal of the material is achieved. The material should be pre-tested for acceptability of the idea, and comprehension of the individual pictures and whole message. The test should be carried out on several different people depending on the target audience and users. ${ }^{14}$ It is also helpful to pre-test the use of the materials. Test the difference between interactive and passive use with different but matched groups.

Long-term outcome and impact assessment is particularly important to evaluate community health learning materials. To evaluate the material, it must have a clear goal and message. The evaluation must measure whether change has taken place and look at the attitudes that have changed, since the target group has been exposed to the media. The evaluation will thus be dependent on some baseline data about beliefs and practices prior to the health education. KAP studies can help measure general success, but the relationship between increased knowledge and a change in attitudes is often difficult to ascertain and may only apply to schoolchildren as in Tanzania. ${ }^{15}$

\section{Conclusion}

Learning materials should be seen as a dynamic part of the learning process and not just something given out to learners with no follow-up or input from the teacher or facilitator. The principles of adult learning should be incorporated into their development and use, so that they are practical, problem oriented and relevant to the learners' situation and learning needs. A variety of learning materials should be used to encourage learning for knowledge, attitudes and skills. Written materials may not be the most appropriate, particularly for health education programmes, other media should be considered and used. The participatory approach to the use of learning materials will not only improve retention of the learning but also increase the attitude and performance skills learning.

Testing of any learning material is necessary to see whether it is valid and effective. Both written and visual materials need to be tested and evaluated. Clear, logical well-set-out materials encourage learning and will enhance the teaching programme.

Learning materials are tools and as such are dependent upon their user. When used in an interactive and participatory approach they can facilitate effective learning, but when badly produced, and poorly used they may be worse than useless, since they can confuse or misinform.

\section{References}

1 Bibliography on Teaching and Learning Material. TALMilep/INFOLEP 1993 (and supplement 1996).

2 Kroehnert G. Basic training for trainers, 2nd edn. New York: McGraw Hill, 1995.

3 Knowles MS et al. The adult leamer, 5th edn. Gulf Publishing Company, 1998.

4 Harden RM, Laidlaw JM, Hesketh EA. AMEE Medical Education Guide No. 16: Study guides-their use and preparation. Medical Teacher, 1999; 21: 248-265.

5 Cavanagh SJ, Coffin DA. Matching instructional preference and teaching styles: a review of the literature. Nurse Educ Today, 1994; 14: 106-110.

${ }^{6}$ Rudd RE, Comings JP. Leamer developed materials: an empowering product. Health Educ Q, 1994; 21: $313-327$.

7 Hayden P. The learner's pocketbook. Management Pocketbooks, 1998. 
${ }^{8}$ Freire P. Pedagogy of the oppressed. New York: The Seabury Press, 1968.

9 Abbatt F, McMahon R. Teaching health-care workers: a practical guide. Macmillan, 1985.

10 Albanese MA, Mitchell S. Problem based learning: a review of literature on its outcomes and implementation issues. Academic Medicine, 1993; 68: 52-81.

11 Abraham B, Van Parijs LG. A search for literature on teaching tools for health professionals. Medical Teacher, 1994; 16: 237-252.

12 Folmer HR. Moynihan MN, Schothorst PM. Testing and evaluating manuals. Amsterdam: Royal Tropical Institute, 1992.

13 Cook BL. Understanding pictures in Papua New Guinea. USA: David C. Cook Foundation, 1981.

14 Haaland A. Pre-testing communication materials. UNICEF, 1984.

15 Van den Broek J, O'Donoghue J et al. Evaluation of a sustained 7-year health education campaign on leprosy in Rufiji District Tanzania. Lepr Rev, 1998; 69: 57-74. 